\title{
Reply to Eric Schlote regarding "Evaluation of dilute hydrogen peroxide technology for continuous room decontamination of multidrug-resistant organisms"
}

\author{
William A. Rutala PhD, $\mathrm{MPH}^{2}$, Hajime Kanamori MD, PhD, MPH ${ }^{2,3}$, Maria F. Gergen MT (ASCP) ${ }^{5}$, \\ Emily E. Sickbert-Bennett PhD, MS ${ }^{1,2}$, Deverick J. Anderson MD, $\mathrm{MPH}^{4}$, Daniel J. Sexton MD ${ }^{4}$, \\ David J. Weber MD, MP ${ }^{1,2}$ and for the CDC Prevention Epicenters Program \\ ${ }^{1}$ Hospital Epidemiology, University of North Carolina Health Care, Chapel Hill, North Carolina, United States, ${ }^{2}$ Division of Infectious Diseases, UNC School of \\ Medicine, Chapel Hill, North Carolina, United States, ${ }^{3}$ Department of Infectious Diseases, Internal Medicine, Tohoku University Graduate School of Medicine, \\ Miyagi Prefecture, Japan, ${ }^{4}$ Division of Infectious Diseases, Duke Center for Antimicrobial Stewardship and Infection Prevention, Duke University Medical Center, \\ Durham, North Carolina, United States and ${ }^{5}$ Lumagenics, Cary, North Carolina, United States
}

To the Editor-We thank Eric Schlote, CEO of Synexis Biodefense Systems, for his letter regarding our article, "Evaluation of dilute hydrogen peroxide technology for continuous room decontamination of multidrug-resistant organisms." As noted in our paper, hospital room environmental surfaces are frequently contaminated and serve as a source for healthcare MDROs. Contact with these contaminated surfaces may result in hand or glove contamination of healthcare personnel that can be transferred to patients. Development of a validated effective method for continuous room disinfection method would provide an important tool for decreasing surface contamination with MDROs and healthcare-associated pathogens.

We acknowledge that the device we tested may not be the device currently marketed by Synexis Biodefense Systems. However, when we conducted our study, we were told that we were studying the device that would be marketed.

We take exception with Mr Schlote's claim that the dilute hydrogen peroxide system marketed by Synexis Biodefense Systems has been validated. Only a single abstract has been published, ${ }^{2}$ and no-peer reviewed, published studies have validated that use of this device can effectively provide continuous decontamination of the environment (eg, surfaces). Furthermore, the one abstract that has been published has substantial limitations: (1) the study used a before-after study design, a relatively weak epidemiologic method; (2) the study assessed the device for only 7 days after installation; (3) the researchers did not measure the concentration of the hydrogen peroxide in the test rooms; and (4) no statistical evaluation was provided. The authors of this abstract recommended further study. Even if a statistical reduction of surface contamination is demonstrated, this method of continuous room disinfection needs to be validated (1) to decrease healthcareassociated infections (HAIs), (2) to be safe for patients and healthcare personnel, and (3) to be cost-effective.
Although we were unable to perform additional studies due to the lack of laboratory capabilities, we have been in contact with colleagues interested in further studies of this methodology. We made several recommendations to them: (1) install the test device consistent with the manufacturer's recommendations; (2) monitor the concentration of hydrogen peroxide at a low concentration produced both at the unit exhaust and at room surfaces; (3) assess relevant healthcare-associated pathogens; (4) use appropriate controls (eg, similar rooms without the test device); (5) monitor microbial reduction quantitatively; (6) monitor compliance with room disinfection (for clinical trials) using a method such as fluorescent dye; (7) perform room cleaning and disinfection per CDC recommendations; and finally (8) assess the impact of HAI rates.

We agree that further studies of self-disinfecting and continuous room disinfection methods are highly important to public health.

\section{Acknowledgments.}

Financial support. No financial support was provided relevant to this article.

Conflicts of interest. Drs. Rutala and Weber are consultants for Professional Disposables International.

\section{References}

1. Rutala WA, Kanamori H, Gergen MF, Sickbert-Bennett EE, Anderson DJ, Sexton DJ, Weber DJ, CDC Prevention Epicenters Program. Evaluation of dilute hydrogen peroxide technology for continuous room decontamination of multidrug-resistant organisms. Infect Control Hosp Epidemiol 2019;40: 1438-1439.

2. Herman CK, Hess J, Cerra C. Dilute hydrogen peroxide technology for reduction of microbial colonization in the hospital setting. Am J Infect Control 2015;43(6):S25-S26.
Author for correspondence: William A. Rutala, E-mail: brutala@med.unc.edu Cite this article: Rutala WA, et al. (2020). Reply to Eric Schlote regarding "Evaluation of dilute hydrogen peroxide technology for continuous room decontamination of multidrugresistant organisms". Infection Control \& Hospital Epidemiology, 41: 738, https://doi.org/ $10.1017 /$ ice.2020.59 